\title{
Bacterial and protozoal agents of canine vector-borne diseases in the blood of domestic and stray dogs from southern Portugal
}

\author{
Carla Maia ${ }^{1,2,3^{*}}$, Bruno Almeida ${ }^{3}$, Mónica Coimbra ${ }^{4}$, Maria Catarina Fernandes ${ }^{3}$, José Manuel Cristóvão ${ }^{1,2}$, \\ Cláudia Ramos ${ }^{1}$, Ângela Martins ${ }^{5}$, Filipe Martinhoo ${ }^{6}$, Pedro Silva ${ }^{7}$, Nuno Neves ${ }^{8}$, Mónica Nunes ${ }^{2,9}$, \\ Maria Luísa Vieira ${ }^{2,9}$, Luís Cardoso ${ }^{10}$ and Lenea Campino ${ }^{1,2,11}$
}

\begin{abstract}
Background: The so-called canine vector-borne diseases (CVBD) are caused by a wide range of pathogens transmitted by arthropods. In addition to their veterinary importance, many of these canine vector-borne pathogens can also affect the human population due to their zoonotic potential, a situation that requires a One Health approach. As the prevalence of vector-borne pathogens in cats from southern Portugal has been recently evaluated, the aim of the present study was to assess if the same agents were present in dogs living in the same area, and to assess positivity-associated risk factors.

Methods: One thousand and ten dogs (521 domestic and 489 stray) from veterinary medical centres and animal shelters in southern Portugal were enrolled. Anaplasma spp./Ehrlichia spp., Bartonella spp., Borrelia burgdorferi sensu lato, Babesia spp., Hepatozoon spp. and Leishmania infantum infections were evaluated by polymerase chain reaction (PCR) assays in blood samples.

Results: Sixty-eight (6.7\%) dogs were PCR-positive to at least one of the tested CVBD agent species, genera or complex, including one dog found positive to two different genera. Nineteen (1.9\%) dogs were positive to Anaplasma spp./Ehrlichia spp., eight (0.8\%) to B. burgdorferi s.l., 31 (3.1\%) to Hepatozoon spp. and 11 (1.1\%) to L. infantum. Anaplasma platys, Ehrlichia canis, B. burgdorferis.I. and Hepatozoon canis were identified by DNA sequencing, including one animal confirmed with both A. platys and H. canis. Furthermore, Wolbachia spp. was amplified in blood from four dogs. None of the tested dogs was positive by PCR for Bartonella spp. or Babesia spp.

Conclusions: The molecular identification of CVBD agents in southern Portugal, some of them with zoonotic concern, reinforces the importance to alert the veterinary community, owners and public health authorities to prevent the risk of transmission of vector-borne pathogens among dogs and to other vertebrate hosts including humans. The prevalence of the selected pathogens was lower than that previously found in cats from the same region, probably because veterinarians and owners are more aware of them in the canine population and control measures are used more often.
\end{abstract}

Keywords: Dogs, Canine vector-borne diseases, Bacteria, Protozoa, Portugal, Polymerase chain reaction

\footnotetext{
* Correspondence: carlamaia@ihmt.unl.pt

'Unidade de Parasitologia Médica, Instituto de Higiene e Medicina Tropical

(IHMT), Universidade Nova de Lisboa (UNL), Lisbon, Portugal

${ }^{2}$ Global Health and Tropical Medicine, IHMT-UNL, Lisbon, Portugal

Full list of author information is available at the end of the article
} 


\section{Background}

Canine vector-borne diseases (CVBD) comprise a group of globally distributed and spreading illnesses that are caused by a wide range of pathogens transmitted by arthropods [1-4]. In addition to their veterinary importance, many of these canine vector-borne pathogens can also affect the human population due to their zoonotic potential, a situation that requires a One Health approach [5,6].

Anaplasma phagocytophilum and Anaplasma platys cause canine granulocytic anaplasmosis and infectious canine cyclic thrombocytopenia, respectively. Both agents can infect a range of domestic and wild vertebrate hosts, including dogs and humans [7-10]. A. phagocytophilum is transmitted by ticks of the genus Ixodes and A. platys presumably by the Rhipicephalus sanguineus ticks. In Portugal $A$. platys DNA has been detected in clinically suspect dogs living in the north and south of Portugal [11,12], while the overall national seroprevalence of Anaplasma spp. has ranged from 4.5\% in apparently healthy to $9.2 \%$ in clinically suspect dogs [3]. Ehrlichia canis (transmitted by $R$. sanguineus) is a causative agent of acute or chronic canine monocytic ehrlichiosis. E. canis has been molecularly detected in dogs from the north $[12,13]$ and from the south of Portugal [14]. Seroprevalence at the national level ranged from $4.1 \%$ in apparently healthy dogs to $16.4 \%$ in animals clinically suspected of a CVBD [3].

Seven Bartonella species transmitted by several arthropod vectors, including fleas and Ixodes spp. ticks, have been implicated as canine pathogens [15]. To date, no dog with Bartonella spp. infection has been reported in Portugal. Spirochetes belonging to the Borrelia burgdorferi sensu lato complex are the agents of Lyme borreliosis. In Europe, B. burgdorferi s.l. is mainly transmitted by I. ricinus [16]. Though few infected dogs show similar clinical signs, most of them are subclinical hosts [17] and can be sentinels for this infection. In Portugal, seropositivity to $B$. burgdorferi s.l. has ranged from $0.2 \%$ in apparently healthy dogs to $0.5 \%$ in clinical suspected animals in a countrywide investigation [3].

Canine piroplasmosis or babesiosis, mainly caused by several Babesia spp. haemoparasites, is a protozoal tick-borne disease with worldwide distribution [18]. Babesia canis (transmitted by Dermacentor reticulatus), Babesia vogeli (transmitted by $R$. sanguineus) and the Babesia microti-like piroplasm (syn. Theileria annae) were molecularly confirmed for the first time in Portugal in dogs from the north of the country $[19,20]$. Canine hepatozoonosis caused by the protozoan Hepatozoon canis transmitted by the ingestion of $R$. sanguineus is a common infection of dogs from the Old World [21]. H. canis has already been molecularly detected in dogs from the north $[13,22]$ and from the south of Portugal [23]. Canine leishmaniosis (CanL), a zoonotic disease endemic in southern Europe is caused by the protozoan
L. infantum transmitted by Phlebotomus spp. sand flies [24]. CanL is endemic in Portugal, with an overall national seroprevalence of $6.3 \%$ [25].

As the prevalence of vector-borne pathogens in cats from southern Portugal was recently evaluated [26], the aim of the present study was to assess if the same agents with veterinary and zoonotic importance were present in dogs living in the same region, and to assess positivityassociated risk factors.

\section{Methods}

\section{Animals and samples}

From December 2011 to April 2014, a total of 1,010 dogs (521 domestic and 489 stray), from veterinary medical centres and animal shelters in southern Portugal, were studied (Table 1). Animals were from the districts of Lisbon $(n=305)$, Setúbal $(n=453$, which include 24 . dogs from the contiguous districts of Évora and Beja) and Faro $(\mathrm{n}=252)$.

Domestic dogs were randomly included after owners' informed consent. Consent for enrolment of stray dogs was obtained from the person in charge of each shelter. Out of the 489 stray animals, 457 were sheltered for adoption, and 32 others were captured and euthanized in the scope of official animal control programs.

Whole blood samples (1-2 ml) were collected by cephalic or jugular venipuncture and spotted onto filter paper for DNA extraction. Samples were dried at room temperature and kept at $4^{\circ} \mathrm{C}$ until tested. Whenever available, data on the region, breed, gender, age, living conditions, use of acaricides/insecticides and clinical status (presence or absence of signs compatible with a CVBD) were registered for each dog (Table 1). Clinical signs comprised anorexia, muscular atrophy, dermatological manifestations, epistaxis, exercise intolerance, fever, gastrointestinal alterations, lameness, lethargy, lymphadenopathy, onychogryphosis, ocular manifestations, pale mucous or weight loss.

This study was ethically approved by the boards of the IHMT-UNL and of the Faculty of Veterinary Medicine (ULHT) as complying with the Portuguese legislation for the protection of animals (Law no. 92/1995).

\section{PCR amplification and DNA sequencing}

A commercial kit (Kit Citogene ${ }^{\bullet}$, Citomed, Portugal) was used to extract DNA from blood on filter paper. Four discs of filter paper ( $4 \mathrm{~mm}$ in diameter each) were incubated with lysis buffer $(150 \mu \mathrm{l})$ and $1.5 \mu \mathrm{l}$ of proteinase $\mathrm{K}(20 \mathrm{mg} / \mathrm{ml})$. Further DNA extraction followed the kit manufacturer's instructions.

Positivity to Anaplasma spp./Ehrlichia spp., Bartonella spp., B. burgdorferi s.l., Babesia spp., Hepatozoon spp. and L. infantum DNA in blood samples was tested by PCR according to previously described protocols (Table 2). PCR amplifications were performed in a $25 \mu \mathrm{l}$ final volume 
Table 1 Prevalence of vector-borne pathogen species, gender or complex as detected by PCR in 1,010 dogsfrom southern Portugal

\begin{tabular}{|c|c|c|c|c|c|c|}
\hline \multirow[t]{2}{*}{ Variable//category } & \multirow{2}{*}{$\begin{array}{l}N^{\circ} \text { of characterized } \\
\text { dogs }(\%)\end{array}$} & \multicolumn{5}{|l|}{$\mathrm{N}^{\circ}$ of positive dogs (\%) } \\
\hline & & Anaplasma/Ehrlichia & B. burgdorferi s.l. & Hepatozoon & L. infantum & $\geq 1$ pathogen \\
\hline Region & 1,010 & & & & & \\
\hline Lisboa & $305(30.2)$ & $1(0.3)^{\mathrm{a}}$ & $1(0.3)$ & $2(0.7)^{a}$ & $7(2.3)$ & $11(3.6)^{a}$ \\
\hline Setúbal & $453(44.9)$ & $2(0.4)^{b}$ & $3(0.7)$ & $10(2.2)^{b}$ & $3(0.7)$ & $17(3.8)^{b}$ \\
\hline Algarve & $252(25.0)$ & $16(6.3)^{a, b}$ & $4(1.6)$ & $19(7.5)^{a, b}$ & $1(0.4)$ & $40(15.9)^{a, b}$ \\
\hline Breed & 793 & & & & & \\
\hline Defined & $344(43.4)$ & $4(1.2)$ & $3(0.9)$ & $8(2.3)$ & $6(1.7)$ & $21(6.1)$ \\
\hline Mongrel & $449(56.6)$ & $12(2.7)$ & $5(1.1)$ & $18(4.0)$ & $4(0.9)$ & $39(8.7)$ \\
\hline Gender & 1,004 & & & & & \\
\hline Female & $504(50.2)$ & $9(1.8)$ & $5(1.0)$ & $15(3.0)$ & $4(0.8)$ & $33(6.5)$ \\
\hline Male & $500(49.8)$ & $9(1.8)$ & $3(0.6)$ & $14(2.8)$ & $7(1.4)$ & $33(6.6)$ \\
\hline Age (months) & 938 & & & & & \\
\hline$[1-11]$ & $73(7.8)$ & $3(4.1)$ & $2(2.7)$ & $0(0.0)$ & $0(0.0)$ & $5(6.8)$ \\
\hline [12-83] & $576(61.4)$ & $10(1.7)$ & $4(0.7)$ & $15(2.6)$ & $7(1.2)$ & $36(6.3)$ \\
\hline$[84-228]$ & $289(30.8)$ & $3(1.0)$ & $1(0.3)$ & $7(2.4)$ & $3(1.0)$ & $14(4.8)$ \\
\hline Lifestyle & 1,010 & & & & & \\
\hline Domestic & $521(51.6)$ & $15(2.9)^{\mathrm{a}}$ & $6(1.2)$ & $19(3.6)$ & $6(1.2)$ & $45(8.6)^{a}$ \\
\hline Stray & $489(48.4)$ & $4(0.8)^{\mathrm{a}}$ & $2(0.4)$ & $12(2.5)$ & $5(1.0)$ & $23(4.7)^{\mathrm{a}}$ \\
\hline Housing & 852 & & & & & \\
\hline Indoors & $63(7.4)$ & $0(0.0)$ & $0(0.0)$ & $0(0.0)$ & $0(0.0)$ & $0(0.0)^{a, b}$ \\
\hline Mixed & $182(21.4)$ & $5(2.7)$ & $3(1.6)$ & $11(6.0)$ & $0(0.0)$ & $19(10.4)^{\mathrm{a}}$ \\
\hline Outdoors & $607(71.2)$ & $11(1.8)$ & $4(0.7)$ & $18(3.0)$ & $5(0.8)$ & $38(6.3)^{\mathrm{b}}$ \\
\hline Acaricides-insecticides & 963 & & & & & \\
\hline Yes & $448(46.5)$ & $5(1.5)$ & $4(0.8)$ & $10(2.2)$ & $6(1.3)$ & $25(5.6)$ \\
\hline No & $515(53.5)$ & $12(2.3)$ & $4(0.8)$ & $19(3.7)$ & $4(0.8)$ & $38(7.4)$ \\
\hline Clinical status & 906 & & & & & \\
\hline Non-suspect & $700(77.3)$ & $12(1.7)$ & $5(0.7)$ & $26(3.7)$ & $7(1.0)$ & $49(7.0)$ \\
\hline Suspect & $206(22.7)$ & $6(2.9)$ & $2(1.0)$ & $3(1.5)$ & $3(1.5)$ & $14(6.8)$ \\
\hline Total & 1,010 & $19(1.9)$ & $8(0.8)$ & $31(3.1)$ & $11(1.1)$ & $68(6.7)$ \\
\hline
\end{tabular}

${ }^{\mathrm{a}, \mathrm{b}}$ Statistically significant difference for the same agent between categories of the same variable $(p<0.05)$.

containing $12.5 \mu \mathrm{l}$ of NZYTaq 2x Green Master Mix (Nyztech, Portugal), $1 \mu \mathrm{l}$ of each primer $(10 \mathrm{pmol})$ and $3 \mu \mathrm{l}$ of DNA template. In all amplifications a positive control containing genomic target DNA and a negative control without DNA were included. The reaction mixtures were cycled in a Thermo Electron Corporation ${ }^{\circledR}$ Px2 Termal Cycler (VWR, USA). PCR products were visualized under UV illumination after electrophoresis migration on a $1.5 \%$ gel agarose stained with GreenSafe Premium ${ }^{\bullet}$ (Nzytech), using a 100 bp DNA ladder as a marker.

PCR products were purified with a High Pure PCR Product Purification Kit (Roche ${ }^{\oplus}$, Germany) according to the manufacturer's instructions and directly sequenced (one direction) (Stabvida ${ }^{\oplus}$, Portugal), using the same primers as those used for the DNA amplification.
Species identity of the obtained sequences was determined according to the closest BLAST match (identity $\geq$ 99\% for the first 30 matches) to a GenBank ${ }^{\bullet}$ accession and deposited in DNA Data Bank of Japan (DDBJ) (http://www.DDBJ.nig.ac.jp).

\section{Statistical analysis}

Percentages of positivity to CVBD agents were compared by the Chi-square or Fisher's exact tests. A $p$ value $<0.05$ was considered as statistically significant. The exact binomial test was used to calculate confidence intervals for the proportions, with a 95\% confidence level (CI). Analyses were performed with $\mathrm{SPSS}^{\bullet} 21$ software for Windows and with StatLib. 
Table 2 Primers sets for PCR amplification of CVBD agents

\begin{tabular}{|c|c|c|c|}
\hline Pathogen & Primers & Product size (bp) & Reference \\
\hline \multirow[t]{2}{*}{ Anaplasma spp./Ehrlichia spp. } & EHR16SD: 5'-GGT ACC YAC AGA AGA AGTCC-3' & 345 & {$[27]$} \\
\hline & EHR16SR: 5'-TAG CAC TCA TCG TाT ACAGC-3' & & \\
\hline \multirow[t]{2}{*}{ Bartonella spp. } & 325 s: 5'-CTTCAGATGATGATCCCAAGCCTTCTGGCG-3' & $500-800$ & {$[28]$} \\
\hline & 1100as: 5'-GAACCGACGACCCCCTGCTTGCAAAGCA-3' & & \\
\hline \multirow[t]{6}{*}{ Borrelia burgdorferi s.l. } & Outer primers: & 774 & {$[29]$} \\
\hline & 132f: 5'-TGGTATGGGAGTTTCTGG-3' & & \\
\hline & 905r: 5'-TCTGTCATTGTAGCATCTIT-3' & & \\
\hline & Inner primers: & 604 & {$[29]$} \\
\hline & 220f: 5'-CAGACAACAGAGGGAAAT-3' & & \\
\hline & 823r: 5'-TCAAGTCTATTITGGAAAGCACC-3' & & \\
\hline \multirow[t]{2}{*}{ Babesia spp. } & PIRO-A: 5'-AAT ACC CAA TCC TGA CACAGG G-3' & 400 & {$[27]$} \\
\hline & PIRO-B: 5'-TTA AAT ACG AAT GCC CCCAAC-3' & & \\
\hline \multirow[t]{2}{*}{ Hepatozoon spp. } & HEP-F: 5'-ATA CAT GAG CAA AAT CTC AAC-3' & $626-666$ & {$[30]$} \\
\hline & HEP-R: 5'-CTT ATT ATT CCA TGC TGC AG-3' & & \\
\hline \multirow[t]{2}{*}{ Leishmania infantum } & MC1: 5'-GTTAGCCGATGGTGGTCTTG-3' & 447 & {$[31]$} \\
\hline & MC2: 5'-CACCCATTTTCCGATTTG-3' & & \\
\hline
\end{tabular}

\section{Results}

Sixty-eight (6.7\%; CI: 5.3-8.5\%) dogs were PCR-positive to at least one of the tested species, genera or complex of CVBD agents (Table 1). Nineteen (1.9\%; CI: 1.1-2.9\%) dogs were positive to Anaplasma spp./Ehrlichia spp., eight (0.8\%; CI: 0.3-1.5\%) to B. burgdorferi s.l., 31 (3.1\%; CI: 2.1-4.3) to Hepatozoon spp. and 11(1.1\%; CI: 0.5-1.9) to L. infantum (Table 3). Wolbachia spp. DNA (amplified with the same primers used to detect Anaplasma spp./Ehrlichia spp.) was detected in four dogs, while DNA of Bartonella spp. or Babesia spp. was not amplified from any dog in the study.

As shown in Table 1, the prevalence of Anaplasma spp/ Ehrlichia spp. was statistically higher in domestic dogs. Positivity to these bacteria and to Hepatozoon spp. was higher in dogs living in the Algarve region. Statistically significant differences were also found for PCR positivity to at least one of the studied agents in domestic dogs, in dogs with access to outdoors and in dogs living in the Algarve region.

Sequencing confirmed $A$. platys in five, E. canis in five, $B$. burgdorferis.l. in six and $H$. canis in 18 dogs, including one animal with both $A$. platys and $H$. canis (Table 3 ); and revealed Wolbachia spp. (DDBJ accessions: LC018189 to LC018192) in four dogs.

\section{Discussion}

This is the most comprehensive study carried out in dogs from southern Portugal on the prevalence of infection

Table 3 Single and mixed PCR-positivity to species, genera and/or complex of CVBD agents in 1,010 dogs from southern Portugal

\begin{tabular}{|c|c|c|}
\hline Agents & No. positive dogs (\%) & DDBJ accessions \\
\hline Single infections & $67(6.6)$ & \\
\hline Anaplasma spp./Ehrlichia spp. & $18(1.8)$ & \\
\hline [Anaplasma platys] & {$[4(0.4)]$} & [LC018179 to LC018182] \\
\hline [Ehrlichia canis] & {$[5(0.5)]$} & [LC018184 to LC018188] \\
\hline Borrelia burgdorferi s.l. & $8(0.8)$ & [LC018211 to LC018216] \\
\hline Hepatozoon spp. & $30(3.0)$ & \\
\hline [Hepatozoon canis] & {$[17(1.7)]$} & [LC018193 to LC018209] \\
\hline Leishmania infantum & $11(1.1)$ & \\
\hline Co-infections & $1(0.1)$ & \\
\hline Anaplasma spp./Ehrlichia spp. and Hepatozoon spp. & $1(0.1)$ & \\
\hline [A. platys and H. canis] & {$[1(0.1)]$} & [LC018183 and LC018210] \\
\hline Total & $68(6.7)$ & \\
\hline
\end{tabular}


with CVBD agents as it included domestic and stray animals with and without clinical signs compatible with a vectorborne disease. DNA from these pathogens taken all together was less frequently detected in dogs $(6.7 \% ; p<0.001)$ than in cats $(29.9 \% ; 194 / 649)$ from the same region [26]. Furthermore, only one $(0.1 \%)$ dog was found co-infected (with two pathogens), whereas 29 (4.5\%) cats were positive to two agents and four (0.6\%) cats to three agents [26].

In this study $A$. platys has been molecularly confirmed to infect dogs from the south of the country, corroborating previous detection of this bacterium in dogs $[11,23]$ and in $R$. sanguineus [32] from the same region. The prevalence of positivity to Anaplasma/Ehrlichia in this work (1.9\%) was lower than the 4.0\% obtained in Spain [33] and the 3.7-6.0\% in Italy [34], which might be related with the targeted population. In fact, in the works of Tabar et al. [33] and Trotta et al. [34], all the positive dogs were sick animals with clinical signs compatible with vector-borne diseases and admitted for medical treatment, while in the present work most of the enrolled animals were apparently healthy. Interestingly, in our study most of the animals harbouring Anaplasma/Ehrlichia DNA were from Faro, overlapping the Algarve region, the southern most district of continental Portugal, which seem to follow the trend revealed by Cardoso et al. [3] that the prevalence of antibodies against Anaplasma spp. and E. canis in dogs from southern Portugal was significantly higher than in dogs from the northern and central regions of the country.

In the present work, B. burgdorferi s.l. DNA was amplified from $0.8 \%$ of the screened animals, providing the first molecular evidence of naturally occurring $B$. burgdorferi $\mathrm{s}$. l. infection in dogs from Portugal. The exposure of dogs to these spirochetes was previously demonstrated by specific serology in the Algarve [35] and in the Alentejo and Lisbon regions [3]. Furthermore, B. burgdorferi s.l. genospecies, Borrelia lusitaniae was isolated from humans [36-38] and DNA of B. burgdorferi s.l. was detected in ticks [32,39] and cats from the south of the country [26]. Nevertheless, information on the clinical signs associated with Borrelia infections in dogs and their role as sentinels is still limited [6].

$H$. canis was the most prevalent pathogen detected in all the assessed dogs, with a significantly higher prevalence in animals living in the Algarve. In fact, $H$. canis has recently been identified in dogs [23], in $R$. sanguineus collected from dogs living in this region [32], and also in foxes from the south [40], showing that the protozoan is widespread in this area of the country. Although in this study only three out of the 31 infected dogs presented clinical signs, subclinical infections should not be neglected as they may progress to a severe disease and warrant treatment [41]. Concurrent infections of $H$. canis with other canine pathogens are common [21]; however, in the present work only one animal apparently healthy was co-infected with $A$. platys and the protozoan. Although this individual dog had no clinical signs of a CVBD, co-infections may potentiate disease pathogenesis, altering clinical manifestations associated with single infections [42].

The overall prevalence of $L$. infantum infection in the present study $(1.1 \%)$ was much lower $(p<0.001)$ than the $34.9 \%$ obtained in 152 dogs from Lisbon [43]. The lower detection of Leishmania DNA might be due to the: (i) dynamics of infection over time, which may depend on the abundance and distribution of the proven vector species in conjunction with the number of infected vertebrate hosts [44], and (ii) insufficient data regarding the duration of parasitaemia in infected dogs. In fact, and taking into account a seroprevalence of $18.2 \%$ recently obtained in 170 dogs from the Algarve region [45], PCR with blood should be used to complement serological results and not only by itself to detect Leishmania infection, as it can lead to false negative results, especially in subclinically infected dogs [46].

PCR-positivity to one or more genera/complex of CVBD agents was found to be associated with domestic dogs, with animals living in the Algarve and with an outdoor or mixed (i.e. with outdoor access) housing. In fact, most of the domestic dogs harbouring DNA of the studied pathogens lived in rural areas from the Algarve region and used to spend most of their time exclusively outdoors, thus increasing their exposure to arthropod vectors and the agents they might transmit.

The role of domestic dogs as reservoirs of Bartonella spp. is less clear than for cats, and the former are probably accidental hosts. Nevertheless, they are excellent sentinels for human infections because a similar disease spectrum develops in dogs [47]. Serologic and molecular evidence of Bartonella henselae and Bartonella clarridgeiae exist for cats from the south of Portugal [26,48]. Thus, the nondetection of Bartonella DNA in the present study might be related with differences in immune responses, host preference of particular vectors or innate resistance in dogs to these bacteria. On the other hand, the definitive diagnosis of Bartonella infection is challenging due to the fastidious nature and intracellular tropism of these bacteria for erythrocytes and endothelial cells [49]. According to Perez et al. [50], enrichment culture and subculture, followed by PCR amplification, enhances molecular diagnostic sensitivity in dogs. Thus, it is possible that the PCR done directly from blood samples might have missed some positive cases; nevertheless, the prevalence of infection at the population level, if any, must be very low.

Albeit the detection of $B$. canis, B. vogeli and the $B$. microti-like piroplasm has already been reported in dogs from the north of Portugal $[13,19,20,22]$ and $B$. vogeli in dogs from the south of the country [23], in the present study none of the screened animals harboured piroplasmid DNA. The non-detection of $B$. canis could somehow be 
expected as its vector, $D$. reticulatus, is more abundant in the north of the country. However, the absence of B. vogeli and B. microti-like DNA is more difficult to explain, since both have already been detected in southern Portugal, the former in cats [26], dogs [23] and ticks [32], and the latter in foxes [51]. According to a recent questionnaire-based survey on the distribution of canine babesiosis in western Europe, the annual incidence of this parasitosis in southern Spain, which is geographically close to the area surveyed in this study, was estimated to be $0.0-0.7 \%$ [52]. Furthermore, a $58 \%$ prevalence of antibodies anti-Babesia spp. was reported among 331 dogs from kennels/shelters in southern Portugal [53]. The absence of Babesia spp. infection in the present study might be related with differences in the genetic background/immune system or between vector-dog interactions. Further studies are needed to better understand the epidemiological importance of these findings.

\section{Conclusion}

The identification of CVBD agents in southern Portugal, some of them with zoonotic concern, reinforces the importance to alert the veterinary community, owners and public health authorities to prevent the risk of transmission of vector-borne pathogens among dogs and to other vertebrate hosts including humans. Interestingly, the prevalence of the selected pathogens was much lower than that previously found in cats from the same region [26], probably because veterinarians and owners are much aware of them in the canine population and prophylatic measures such as insecticides and acaricides are used.

\section{Competing interests}

The authors declare that they have no competing interests.

\section{Authors' contributions}

CM planned, designed and supervised the study, and wrote the manuscript; $\mathrm{BA}, \mathrm{CR}$, and MCF collected samples and clinical data, and performed DNA extraction and molecular analyses; AM, FM, JMC, MC, NN and PS collected samples and clinical data; MN performed B. burgdorferi s.l. nested-PCR; LUC performed data analysis and revised the manuscript; MLV and LeC reviewed the manuscript. All authors read and approved the final manuscript.

\section{Acknowledgements \\ This work was supported by Centro de Malária e outras Doenças Tropicais, IHMT-UNL, Portugal, and EU grant FP7-261504 EDENext, and is catalogued by the EDENext Steering Committee as EDENext302 (http://www.edenext.eu). The contents of this publication are the sole responsibility of the authors and do not necessarily reflect the views of the European Commission. The authors thank the cooperation of veterinarians, auxiliary staff, dog owners and shelters that contributed with collection of samples, and also acknowledge Prof. G. Baneth for providing DNA of Anaplasma spp/Ehrlichia spp., Babesia spp. and Hepatozoon spp. CM (SFRH/BPD/44082/2008) and MN (SFRH/BD/78325/2011) hold scholarships from Fundação para a Ciência e a Tecnologia, Ministério da Educação e Ciência, Portugal. \\ Publication of the CVBD10 thematic series has been sponsored by Bayer HealthCare - Animal Health division.}

\section{Author details}

'Unidade de Parasitologia Médica, Instituto de Higiene e Medicina Tropical (IHMT), Universidade Nova de Lisboa (UNL), Lisbon, Portugal. ${ }^{2}$ Global Health and Tropical Medicine, IHMT-UNL, Lisbon, Portugal. ${ }^{3}$ Faculdade de Medicina Veterinária, Universidade Lusófona de Humanidades e Tecnologias, Lisbon,
Portugal. ${ }^{4}$ Clínica Veterinária Porto Seguro, Olhão, Portugal. ${ }^{5}$ Hospital Veterinário da Arrábida, Azeitão, Portugal. ${ }^{6}$ Nyctea Lda., Lisbon, Portugal. ${ }^{7}$ Vetévora, Évora, Portugal. ${ }^{8}$ Clube Animal, Beja, Portugal. ${ }^{9}$ Unidade de Microbiologia Médica, IHMT-UNL, Lisbon, Portugal. ${ }^{10}$ Department of Veterinary Sciences, School of Agrarian and Veterinary Sciences, University of Trás-os-Montes e Alto Douro, Vila Real, Portugal. ${ }^{11}$ Departamento de Ciências Biomédicas e Medicina, Universidade do Algarve, Faro, Portugal.

Received: 15 January 2015 Accepted: 23 February 2015

Published online: 23 March 2015

\section{References}

1. Otranto D, Dantas-Torres F, Breitschwerdt EB. Managing canine vector borne diseases of zoonotic concern: part one. Trends Parasitol. 2009;25:157-63.

2. Baneth G, Bourdeau P, Bourdoiseau G, Bowman D, Breitschwerdt E, Capelli $G$, et al. Vector-borne diseases - constant challenge for practicing veterinarians: recommendations from the CVBD World Forum. Parasit Vectors. 2012;5:55

3. Cardoso L, Mendão C, Madeira de Carvalho L. Prevalence of Dirofilaria immitis, Ehrlichia canis, Borrelia burgdorferi sensu lato, Anaplasma spp. and Leishmania infantum in apparently healthy and CVBD-suspect dogs in Portugal - a national serological stud. Parasit Vectors. 2012;5:62.

4. Miró G, Montoya A, Roura X, Gálvez R, Sainz A. Seropositivity rates for agents of canine vector-borne diseases in Spain: a multicentre study. Parasit Vectors. 2013;6:117.

5. Day MJ. One health: the importance of companion animal vector-borne diseases. Parasit Vectors. 2011;4:49.

6. Mencke N. Future challenges for parasitology: vector control and 'One health' in Europe: the veterinary medicinal view on CVBDs such as tick borreliosis, rickettsiosis and canine leishmaniosis. Vet Parasitol. 2013;195:256-71

7. Doudier B, Olano J, Parola P, Brouqui P. Factors contributing to emergence of Ehrlichia and Anaplasma spp. as human pathogens. Vet Parasitol. 2010;167:149-54.

8. Stuen S, Granquist EG, Silaghi C. Anaplasma phagocytophilum - a widespread multi-host pathogen with highly adaptive strategies. Front Cell Infect Microbiol. 2013;3:31.

9. Arraga-Alvarado CM, Qurollo BA, Parra OC, Berrueta MA, Hegarty BC, Breitschwerdt EB. Molecular evidence of Anaplasma platys infection in two women from Venezuela. Am J Trop Med Hyg. 2014;91:1161-5.

10. Jahfari S, Coipan EC, Fonville M, van Leeuwen AD, Hengeveld P, Heylen D, et al. Circulation of four Anaplasma phagocytophilum ecotypes in Europe. Parasit Vectors. 2014;7:365.

11. Santos AS, Alexandre N, Sousa R, Núncio MS, Bacellar F, Dumler JS. Serological and molecular survey of Anaplasma species infection in dogs with suspected tickborne disease in Portugal. Vet Rec. 2009;164:168-71.

12. Cardoso L, Tuna J, Vieira L, Yisaschar-Mekuzas Y, Baneth G. Molecular detection of Anaplasma platys and Ehrlichia canis in dogs from the North of Portugal. Vet J. 2010;183:232-3.

13. Yisaschar-Mekuzas Y, Jaffe CL, Pastor J, Cardoso L, Baneth G. Identification of Babesia species infecting dogs using reverse line blot hybridization for six canine piroplasms, and evaluation of co-infection by other vector-borne pathogens. Vet Parasitol. 2013;191:367-73.

14. Alexandre N, Santos AS, Núncio MS, Sousa RD, Boinas F, Bacellar F. Detection of Ehrlichia canis by polymerase chain reaction in dogs from Portugal. Vet J. 2009;181:343-4.

15. Diniz PP, Billeter SA, Otranto D, De Caprariis D, Petanides T, Mylonakis ME, et al. Molecular documentation of Bartonella infection in dogs in Greece and Italy. J Clin Microbiol. 2009:47:1565-7.

16. Rizzoli A, Hauffe H, Carpi G, Vourc HG, Neteler M, Rosa R. Lyme borreliosis in Europe. Euro Surveill. 2011;16:19906.

17. Hovius KE, Stark LA, Bleumink-Pluym NM, van de Pol I, Verbeek-de Kruif N, Rijpkema SG, et al. Presence and distribution of Borrelia burgdorferi sensu lato species in internal organs and skin of naturally infected symptomatic and asymptomatic dogs, as detected by polymerase chain reaction. Vet Q. 1999;21:54-8.

18. Solano-Gallego L, Baneth G. Babesiosis in dogs and cats - expanding parasitological and clinical spectra. Vet Parasitol. 2011;181:48-60.

19. Cardoso L, Costa A, Tuna J, Vieira L, Eyal O, Yisaschar-Mekuzas Y, et al. Babesia canis canis and Babesia canis vogeli infections in dogs from northern Portugal. Vet Parasitol. 2008;156:199-204. 
20. Simões PB, Cardoso L, Araújo M, Yisaschar-Mekuzas Y, Baneth G. Babesiosis due to the canine Babesia microti-like small piroplasm in dogs-first report from Portugal and possible vertical transmission. Parasit Vectors. 2011;4:50.

21. Baneth G. Perspectives on canine and feline hepatozoonosis. Vet Parasitol. 2011;181:3-11.

22. Cardoso L, Yisaschar-Mekuzas Y, Rodrigues FT, Costa A, Machado Diz-Lopes $D$, et al. Canine babesiosis in northern Portugal and molecular characterization of vector-borne co-infections. Parasit Vectors. 2010;3:27.

23. René-Martellet M, Lebert I, Chêne J, Massot R, Leon M, Leal A, et al. Diagnosis and incidence risk of clinical canine monocytic ehrlichiosis under field conditions in Southern Europe. Parasit Vectors. 2015;8:3.

24. Campino L, Maia C. The role of reservoirs: canine leishmaniasis. In: Ponte-Sucre A, Padron-Nieves M, Diaz E, editors. Drug resistance in Leishmania parasites - consequences, molecular mechanism and possible treatments. Vienna: Springer Verlag; 2013. p. 45-64.

25. Cortes S, Vaz Y, Neves R, Maia C, Cardoso L, Campino L. Risk factors for canine leishmaniasis in an endemic Mediterranean region. Vet Parasitol. 2012;189:189-96.

26. Maia C, Ramos C, Coimbra M, Bastos F, Martins A, Pinto P, et al. Bacterial and protozoal agents of feline vector-borne diseases in domestic and stray catsfrom southern Portugal. Parasit Vectors. 2014;7:115.

27. Harrus S, Perlman-Avrahami A, Mumcuoglu K, Morick D, Eyal O, Baneth G. Molecular detection of Ehrlichia canis, Anaplasma bovis, Anaplasma platys, Candidatus Midichloria mitochondrii and Babesia canis vogeli in ticks from Israel. Clin Microbiol Infect. 2011;17:459-63.

28. Diniz P, Maggi R, Schwartz D, Cadenas M, Bradley J, Hegarty B, et al. Canine bartonellosis: serological and molecular prevalence in Brazil and evidence of co-infection with Bartonella henselae and Bartonella vinsonii subsp. berkhoffii. Vet Res. 2007:38:697-710.

29. Wodecka B, Leońska A, Skotarczak B. A comparative analysis of molecular markers for the detection and identification of Borrelia spirochaetes in Ixodes ricinus. J Med Microbiol. 2010;59(Pt 3):309-14.

30. Inokuma H, Okuda M, Ohno K, Shimoda K, Onishi T. Analysis of the $18 \mathrm{~S}$ rRNA gene sequence of a Hepatozoon detected in two Japanese dogs. Vet Parasitol. 2002;106:265-71.

31. Cortes S, Rolão N, Ramada J, Campino L. PCR as a rapid and sensitive tool in the diagnosis of human and canine leishmaniasis using Leishmania donovani s.l. -specific kinetoplastid primers. Trans R Soc Trop Med Hyg. 2004;98:12-7.

32. Maia C, Ferreira A, Nunes M, Vieira ML, Campino L, Cardoso L. Molecular detection of bacterial and parasitic pathogens in hard ticks from Portugal. Ticks Tick Borne Dis. 2014;5:409-14.

33. Tabar MD, Francino O, Altet L, Sánchez A, Ferrer L, Roura X. PCR survey of vectorborne pathogens in dogs living in and around Barcelona, an area endemic for leishmaniasis. Vet Rec. 2009;164:112-6.

34. Trotta M, Fogliazza A, Furlanello T, Solano-Gallego L. A molecular and serological study of exposure to tick-borne pathogens in sick dogs from Italy. Clin Microbiol Infect. 2009;15:62-3.

35. Alexandre NML. Estudo clínico e epidemiológico da febre botonosa, ehrlichiose canina e borreliose de Lyme numa população de canídeos domésticos do Algarve. MSc dissertation. Lisbon: Technical University of Lisbon, Faculty of Veterinary Medicine; 2006.

36. Collares-Pereira M, Couceiro S, Franca I, Kurtenbach K, Schäfer SM, Vitorino $L$, et al. First isolation of Borrelia lusitaniae from a human patient. J Clin Microbiol. 2004:42:1316-8.

37. de Carvalho IL, Fonseca JE, Marques JG, Ullmann A, Hojgaard A, Zeidner N, et al. Vasculitis-like syndrome associated with Borrelia lusitaniae infection. Clin Rheumatol. 2008:27:1587-91.

38. de Carvalho IL, Zeidner N, Ullmann A, Hojgaard A, Amaro F, Zé-Zé L, et al. Molecular characterization of a new isolate of Borrelia lusitaniae derived from Apodemus sylvaticus in Portugal. Vector Borne Zoonotic Dis. 2010;10:531-4.

39. Baptista S, Quaresma A, Aires T, Kurtenbach K, Santos-Reis M, Nicholson M, et al. Lyme borreliosis spirochetes in questing ticks from mainland Portugal. Int J Med Microbiol. 2004;293:109-16.

40. Cardoso L, Cortes HC, Eyal O, Reis A, Lopes AP, Vila-Viçosa MJ, et al. Molecular and histopathological detection of Hepatozoon canis in red foxes (Vulpes vulpes) from Portugal. Parasit Vectors. 2014;7:113.

41. Baneth $\mathrm{G}$, Weigler $\mathrm{B}$. Retrospective case-control study of hepatozoonosis in dogs in Israel. J Vet Intern Med. 1997:11:365-70.
42. De Tommasi AS, Otranto D, Dantas-Torres F, Capelli G, Breitschwerdt EB, de Caprariis D. Are vector-borne pathogen co-infections complicating the clinical presentation in dogs? Parasit Vectors. 2013;6:97.

43. Maia C, Gomes J, Cristóvão J, Nunes M, Martins A, Rebêlo E, et al. Feline Leishmania infection in a canine leishmaniasis endemic region, Portugal. Vet Parasitol. 2010;174:336-40.

44. Maia C, Dionísio L, Afonso MO, Neto L, Cristóvão JM, Campino L. Leishmania infection and host-blood feeding preferences of phlebotomine sandflies and canine leishmaniasis in an endemic European area, the Algarve Region in Portugal. Mem Inst Oswaldo Cruz. 2013;108:481-7.

45. Maia C, Coimbra M, Ramos C, Cristóvão JM, Cardoso L, Campino L. Serological investigation of Leishmania infantum, Dirofilaria immitis and Angiostrongylus vasorum in dogs from southern Portugal. Parasit Vectors (in press).

46. Maia C, Campino L. Methods for diagnosis of canine leishmaniasis and immune response to infection. Vet Parasitol. 2008;158:274-87.

47. Chomel B, Boulouis H, Maruyama S, Breitschwerdt E. Bartonella spp. in pets and effect on human health. Emerg Infect Dis. 2006;12:389-94.

48. Alves AS, Milhano N, Santos-Silva M, Santos AS, Vilhena M, de Sousa R. Evidence of Bartonella spp., Rickettsia spp. and Anaplasma phagocytophilum in domestic, shelter and stray cat blood and fleas, Portugal. Clin Microbiol Infect. 2009:15:1-3.

49. Breitschwerdt EB, Maggi RG, Chomel BB, Lappin MR. Bartonellosis: an emerging infectious disease of zoonotic importance to animals and human beings. J Vet Emerg Crit Care (San Antonio). 2010;20:8-30.

50. Perez C, Maggi RG, Diniz PP, Breitschwerdt EB. Molecular and serological diagnosis of Bartonella infection in 61 dogs from the United States. J Vet Intern Med. 2011:25:805-10.

51. Cardoso L, Cortes HC, Reis A, Rodrigues P, Simões M, Lopes AP, et al. Prevalence of Babesia microti-like infection in red foxes (Vulpes vulpes) from Portugal. Vet Parasitol. 2013;196:90-5.

52. Halos L, Lebert I, Abrial D, Danlois F, Garzik K, Rodes D, et al. Questionnairebased survey on the distribution and incidence of canine babesiosis in countries of Western Europe. Parasite. 2014;21:13.

53. Menn B, Lorentz S, Naucke TJ. Imported and travelling dogs as carriers of canine vector-borne pathogens in Germany. Parasit Vectors. 2010;3:34.

\section{Submit your next manuscript to BioMed Central and take full advantage of:}

- Convenient online submission

- Thorough peer review

- No space constraints or color figure charges

- Immediate publication on acceptance

- Inclusion in PubMed, CAS, Scopus and Google Scholar

- Research which is freely available for redistribution 